\title{
Article \\ Combination Assessment of Diffusion-Weighted Imaging and T2-Weighted Imaging Is Acceptable for the Differential Diagnosis of Lung Cancer from Benign Pulmonary Nodules and Masses
}

\author{
Katsuo Usuda ${ }^{1, *(\mathbb{D})}$, Masahito Ishikawa ${ }^{1}$, Shun Iwai ${ }^{1}$, Yoshihito Iijima ${ }^{1}$, Nozomu Motono ${ }^{1}(\mathbb{D}$, \\ Munetaka Matoba ${ }^{2}$, Mariko Doai ${ }^{2}$, Keiya Hirata ${ }^{3}$ and Hidetaka Uramoto ${ }^{1}$
}

1 Department of Thoracic Surgery, Kanazawa Medical University, Ishikawa 920-0293, Japan; masa-i@kanazawa-med.ac.jp (M.I.); mhg1214@kanazawa-med.ac.jp (S.I.); y-iijima@kanazawa-med.ac.jp (Y.I.); motono@kanazawa-med.ac.jp (N.M.); hidetaka@kanazawa-med.ac.jp (H.U.)

2 Department of Radiology, Kanazawa Medical University, Ishikawa 920-0293, Japan; m-matoba@kanazawa-med.ac.jp (M.M.); doaimari@kanazawa-med.ac.jp (M.D.)

3 MRI Center, Kanazawa Medical University Hospital, Ishikawa 920-0293, Japan; keiya@kanazawa-med.ac.jp

* Correspondence: usuda@kanazawa-med.ac.jp; Tel.: +81-76-286-2211; Fax: +81-76-286-1207

check for updates

Citation: Usuda, K.; Ishikawa, M.; Iwai, S.; Iijima, Y.; Motono, N.; Matoba, M.; Doai, M.; Hirata, K.; Uramoto, H. Combination Assessment of Diffusion-Weighted Imaging and T2-Weighted Imaging Is Acceptable for the Differential Diagnosis of Lung Cancer from Benign Pulmonary Nodules and Masses. Cancers 2021, 13, 1551.

https://doi.org/10.3390/cancers13071551

Academic Editors: Enrico Cassano and Filippo Pesapane

Received: 24 February 2021

Accepted: 25 March 2021

Published: 28 March 2021

Publisher's Note: MDPI stays neutral with regard to jurisdictional claims in published maps and institutional affiliations.

Copyright: (c) 2021 by the authors Licensee MDPI, Basel, Switzerland. This article is an open access article distributed under the terms and conditions of the Creative Commons Attribution (CC BY) license (https:/ / creativecommons.org/licenses/by/ $4.0 /)$.
Simple Summary: The purpose of this study is to determine whether the combination assessment of DWI and T2WI improves the diagnostic ability for differential diagnosis of lung cancer from benign pulmonary nodules and masses (BPNMs). As using the OCV $\left(1.470 \times 10^{-3} \mathrm{~mm}^{2} / \mathrm{s}\right)$ for ADC, the sensitivity was $83.9 \%(220 / 262)$, the specificity $63.4 \%(33 / 52)$, and the accuracy $80.6 \%(253 / 314)$. As using the OCV (2.45) for T2 CR, the sensitivity was $89.7 \%(235 / 262)$, the specificity $61.5 \%(32 / 52)$, and the accuracy $85.0 \%(267 / 314)$. In 212 PNMs which were judged to be malignant by both DWI and T2WI, 203 PNMs (95.8\%) were lung cancers. In 33 PNMs which were judged to be benign by both DWI and T2WI, 23 PNMs (69.7\%) were BPNMs. The combined assessment of DWI and T2WI could judge PNMs more precisely and would be acceptable for differential diagnosis of PNMs.

Abstract: The purpose of this study is to determine whether the combination assessment of DWI and T2-weighted imaging (T2WI) improves the diagnostic ability for differential diagnosis of lung cancer from benign pulmonary nodules and masses (BPNMs). The optimal cut-off value (OCV) for differential diagnosis was set at $1.470 \times 10^{-3} \mathrm{~mm}^{2} / \mathrm{s}$ for apparent diffusion coefficient (ADC), and at 2.45 for T2 contrast ratio (T2 CR). The ADC $\left(1.24 \pm 0.29 \times 10^{-3} \mathrm{~mm}^{2} / \mathrm{s}\right)$ of lung cancer was significantly lower than that $\left(1.69 \pm 0.58 \times 10^{-3} \mathrm{~mm}^{2} / \mathrm{s}\right)$ of BPNM. The T2 CR $(2.01 \pm 0.52)$ of lung cancer was significantly lower than that $(2.74 \pm 1.02)$ of BPNM. As using the OCV for ADC, the sensitivity was $83.9 \%(220 / 262)$, the specificity $63.4 \%(33 / 52)$, and the accuracy $80.6 \%(253 / 314)$. As using the OCV for T2 CR, the sensitivity was $89.7 \%(235 / 262)$, the specificity $61.5 \%(32 / 52)$, and the accuracy $85.0 \%$ (267/314). In 212 PNMs which were judged to be malignant by both DWI and T2WI, 203 PNMs (95.8\%) were lung cancers. In 33 PNMs which were judged to be benign by both DWI and T2WI, 23 PNMs (69.7\%) were BPNMs. The combined assessment of DWI and T2WI could judge PNMs more precisely and would be acceptable for differential diagnosis of PNMs.

Keywords: magnetic resonance imaging (MRI); diffusion-weighted magnetic resonance imaging (DWI); T2-weighted imaging (T2WI); lung cancer; pulmonary nodule and mass (PNM); pulmonary abscess; apparent diffusion coefficient (ADC)

\section{Introduction}

Pulmonary nodules and masses (PNMs) are common medical problems for which management can be quite complex. Among the PNMs, lung cancer is the most serious disease related to deaths, and its correct diagnosis is essential for patients. CT is the imaging 
standard of choice for assessing PNMs in daily practice. 18-fluoro-2-deoxy-glucose positron emission tomography/computed tomography (FDG-PET/CT) is valuable for discriminating lung cancer from benign pulmonary nodules and masses (BPNMs) [1]. FDG-PET/CT has been widely adopted for its imaging modality of PNMs. Its maximum standardized uptake value (SUVmax) shows glucose uptake and expresses how invasive the cancer is. However, FDG-PET/CT is very costly, and its assessment is difficult because there are cases of false-negative results for well-differentiated pulmonary adenocarcinomas [2] and small volumes of metabolically active tumors [3], and false-positive results for inflammatory nodules [4].

In the past, the use of pulmonary magnetic resonance imaging (MRI) has been limited by several weaknesses, including low signal-to-noise ratios due to low proton density in the lungs, loss of signal related to cardiac and respiratory motion, and artifacts related to the magnetic susceptibility differences between air and soft tissue. MRI for lung cancer has been limitedly performed in the cases of mediastinum invasion or chest wall invasion of lung cancer partly due to the report of Webb et al. of the Radiologic Diagnostic Oncology Group in 1991 [5]. Recently MRI technology has advanced dramatically. Diffusion-weighted magnetic resonance imaging (DWI) has been applied both to discriminate PNMs and to evaluate response evaluation of treatment for lung cancer. DWI has been utilized for detecting the free diffusion of water molecules (Brownian motion) with areas of restricted diffusion. Its apparent diffusion coefficient (ADC) value shows a quantitative parameter of the diffusion of water molecules in biological tissues, and the ADCs of malignant tumors are significantly lower than those of normal tissues or benign lesions [6]. All the meta-analyses mentioned that DWI could differentiate malignancy from benignity for PNMs [7-9] and might decrease unnecessary biopsy rates and complications of biopsies [10].

In practice, it is sometimes difficult to differentiate a pulmonary abscess from lung cancer by DWI because a pulmonary abscess shows strongly restricted diffusion like lung cancer. T2-weighted imaging (T2WI) is an essential MRI examination. DWI is related to T2WI and influenced by T2-shine through. The usefulness of T2WI was demonstrated, especially in the evaluation of high-intensity fluid materials associated with the organ lesions, such as intratumoral necrosis, cysts, mucus, hemorrhage, or edema [11,12]. Actually, $\mathrm{T} 2 \mathrm{WI}$ is reliable for the diagnosis of cystic mediastinal tumors. Lung cancer is likely to show lower intensity compared to BPNMs in T2WI.

Although DWI can be valuable for differential diagnosis of lung cancer from BPNMs, the diagnostic capability may not be perfect. The interpretation of small metastatic nodules, nonsolid adenocarcinoma, some granulomas, and active inflammatory nodules should be approached with caution [13].

The purpose of this study is to determine whether the combination assessment of DWI and T2WI improves the diagnostic ability for discriminating lung cancer from BPNMs.

\section{Materials and Methods}

\subsection{Eligibility}

The study protocol for examining MRI in patients with PNMs was approved by the ethical committee of Kanazawa Medical University (the approval number: No. I302). Written informed consent for MRI was obtained from each patient after discussing the risks and benefits of the examinations. The study was conducted according to the guidelines of the Declaration of Helsinki.

\subsection{Patients}

Patients who had lung cancer or a BPNM in chest X-ray were examined with plain CT first. The primary diagnosis of lung cancer or BPNM was performed by chest CT. In the patients who had primary lung cancers or BPNMs in CT, and had MRI examinations before pathological diagnosis and bacterial diagnosis from May 2009 to April 2020, 314 patients qualified for detailed analysis of MRI with T2WI and DWI (Table 1). Patients included in the study had PNMs with a maximum size of $150 \mathrm{~mm}$ or less (range 5-150 mm, mean 
$31.9 \mathrm{~mm}$ ) in CT, and which had no definitive calcification. Most of the PNMs were pathologically diagnosed by resection, or through a flexible bronchoscopy. The other remaining PNMs were diagnosed by bacterial culture or roentgenographically follow-up study. The PNMs were diagnosed as benign when the PNMs decreased in size or disappeared upon review of retrospective chest x-ray films or CT. Pure ground-glass-opacity (GGO)-type lung cancers were excluded from this study. None of the patients had received prior treatment. 196 patients were male and 118 were female. Their mean age was 68 years old (range 37 to 85). There were 262 lung cancers and 52 BPNMs. Out of 262 patients with lung cancer, 226 of those patients that were enrolled in this study were also used in another paper [14]. The diagnosis was made pathological in all lung cancers. For 262 lung cancers, there were 183 adenocarcinomas, 60 squamous cell carcinomas, 4 large cell neuroendocrine carcinomas (LCNECs), 3 large cell carcinomas, 3 adenosquamous carcinomas, 2 carcinoids, 6 small cell carcinomas and 1 carcinosarcoma. TNM classification and the lymph node stations of lung cancer were classified according to the new definitions in UICC 8 [15]. There were 2 pathological T1mi (pT1 mi) carcinomas, 70 pT1a carcinomas, 49 pT1b carcinomas, 3 pT1c carcinomas, 78 pT2a carcinomas, 19 pT2b carcinomas, 35 pT3 carcinomas, and 6 pT4 carcinomas. There were 209 pathological N0 (pN0) carcinomas, 33 pN1 carcinomas, and $20 \mathrm{pN} 2$ carcinomas. There were 254 pathological M0 (pM0) carcinomas, 5 pM1a carcinomas, 2 pM1b carcinomas and $1 \mathrm{M} 1 \mathrm{c}$ carcinoma. The 5 pM1a carcinomas were due to pleural dissemination or malignant effusion at operation. The $2 \mathrm{pM} 1 \mathrm{~b}$ carcinomas were due to single brain metastasis. The $1 \mathrm{M} 1 \mathrm{c}$ carcinoma was due to metastasis to the liver and stomach. Brain metastasis was diagnosed by brain enhanced MRI, and metastasis to liver and stomach was diagnosed by biopsy after FDG-PET/CT. There were 118 pStage IA carcinomas, 58 pStage IB carcinomas, 26 pStage IIA carcinomas, 21 pStage IIB carcinomas, 30 pStage IIIA carcinomas, 1 pStage IIIB carcinoma, 7 pStage IVA carcinomas and 1 pStage IVB carcinoma.

Table 1. Patients' clinical data.

\begin{tabular}{|c|c|c|c|}
\hline & \multicolumn{2}{|c|}{ Lung Cancer } & Benign Pulmonary Nodule and Mass (BPNM) \\
\hline No. of patients & & 262 & 52 \\
\hline Male/Female & & $164 / 98$ & $32 / 20$ \\
\hline \multirow[t]{8}{*}{ Cell type } & adenocarcinoma & 183 & \\
\hline & squamous cell ca. & 60 & \\
\hline & LCNEC & 4 & \\
\hline & Large cell ca. & 3 & \\
\hline & Adenosquamous ca. & 3 & \\
\hline & Carcinoid & 2 & \\
\hline & Small cell ca. & 6 & \\
\hline & Carcinosarcoma & 1 & \\
\hline \multirow[t]{8}{*}{$\mathrm{pT}$} & $\mathrm{T} 1 \mathrm{mi}$ & 2 & \\
\hline & T1a & 70 & \\
\hline & $\mathrm{T} 1 \mathrm{~b}$ & 49 & \\
\hline & $\mathrm{T} 1 \mathrm{c}$ & 3 & \\
\hline & $\mathrm{T} 2 \mathrm{a}$ & 78 & \\
\hline & $\mathrm{T} 2 \mathrm{~b}$ & 19 & \\
\hline & T3 & 35 & \\
\hline & $\mathrm{T} 4$ & 6 & \\
\hline \multirow[t]{3}{*}{$\mathrm{pN}$} & N0 & 209 & \\
\hline & N1 & 33 & \\
\hline & N2 & 20 & \\
\hline \multirow[t]{4}{*}{$\mathrm{pM}$} & M0 & 254 & \\
\hline & M1a & 5 & \\
\hline & M1b & 2 & \\
\hline & M1c & 1 & \\
\hline
\end{tabular}


Table 1. Cont.

\begin{tabular}{|c|c|c|c|c|c|}
\hline \multirow[b]{2}{*}{ pStage } & \multicolumn{2}{|c|}{ Lung Cancer } & \multicolumn{3}{|c|}{ Benign Pulmonary Nodule and Mass (BPNM) } \\
\hline & Stage IA & 118 & & & \\
\hline & Stage IB & 58 & & & \\
\hline & Stage IIA & 26 & & & \\
\hline & Stage IIB & 21 & & & \\
\hline & Stage IIIA & 30 & & & \\
\hline & Stage IIIB & 1 & & & \\
\hline & Stage IVA & 7 & & & \\
\hline & Stage IVB & 1 & & & \\
\hline \multirow[t]{9}{*}{ Causes of BPNM } & & & Inflammatory & Mycobacterial disease & 13 \\
\hline & & & & Pneumonia & 13 \\
\hline & & & & Pulmonary abscess & 8 \\
\hline & & & & Pulmonary scar & 3 \\
\hline & & & & Organized pneumonia & 2 \\
\hline & & & & Other & 2 \\
\hline & & & Non-inflammatory & Hamartoma & 5 \\
\hline & & & & Pulmonary sequestration & 2 \\
\hline & & & & Other & 4 \\
\hline \multirow[t]{3}{*}{$\begin{array}{c}\text { Diagnosis and } \\
\text { therapy }\end{array}$} & Resection & 262 & & Resection & 36 \\
\hline & & & & Bacterial culture & 3 \\
\hline & & & & $\begin{array}{l}\text { Decreased size or } \\
\text { disappearance }\end{array}$ & 13 \\
\hline
\end{tabular}

For 52 BPNMs, there were 41 inflammatory BPNMs [Mycobacterial disease 13 (tuberculosis 5 , nontuberculous mycobacteria 8 ), pneumonia 13 , pulmonary abscess 8 , pulmonary scar 3, organized pneumonia 2, pulmonary granuloma 1 and sarcoidosis 1 , and 11 noninflammatory BPNMs (hamartoma 5, pulmonary sequestration 2, nodular lymphoid hyperplasia 1, inflammatory myofibroblastic tumor 1, encapsulated pleural effusion 1 and pleural cyst 1). Twenty-six BPNMs were diagnosed pathologically by resection. Thirteen BPNMs were diagnosed as mycobacterial disease by bacterial culture (3) or resection (10). The remaining 13 BPNMs were diagnosed as pneumonia by decreased size or disappearance of the BPNMs.

\subsection{MR Imaging}

All MR images were produced with a $1.5 \mathrm{~T}$ superconducting magnetic scanner (Magnetom Avanto, Siemens, Erlangen, Germany) with two anterior six-channel body phasedarray coils and two posterior spinal clusters (six-channels each). The conventional MR images consisted of a coronal T1-weighted spin-echo sequence and coronal and axial T2-weighted fast spin-echo.

Examination of the 1.5-T MRI was performed as follows: T2WI was obtained in a turbo spin echo (TSE); TR/TE, 4400-6000/74 ms; FOV, $350 \times 240 \mathrm{~mm}$; matrix, $320 \times 198$; thickness, $6.0 \mathrm{~mm}$ ), Flip angle $90^{\circ}$. T1-weighted imaging (T1WI) was obtained in gradient recalled echo (GRE) VIBE; TR/TE, 6.54/4.78 ms; FOV, $380 \times 240 \mathrm{~mm}$; matrix, $256 \times 151$; thickness, $3.5 \mathrm{~mm}$ ). DWIs using a single-shot echo-planar method were applied with a slice thickness of $6 \mathrm{~mm}$ under SPAIR (spectral attenuated inversion recovery) with a respiratory triggered scan with the following parameter: TR/TE/flip angle, 3000-4500/65/90; diffusion gradient encoding in three orthogonal directions; $b$ value $=0$ and $800 \mathrm{~s} / \mathrm{mm}^{2}$; field of view, $350 \mathrm{~mm}$; matrix size, $128 \times 128$.

After image reconstruction, a two-dimensional (2D) round or elliptical region of interest (ROI) was drawn on the lesion which was detected visually on the ADC map with reference to T2-weighted or $\mathrm{CT}$ image. The procedures were repeated three times and the minimum ADC value was obtained. T2 contrast ratio (T2 CR) of a PNM was defined based on the definition of Koyama et al. [16]: T2 CR = the ratio of T2 signal intensity of a PNM 
divided by T2 signal intensity of a rhomboid muscle. The ROI placed over the muscle was fixed at $120 \mathrm{~mm}^{2}$ (a round of $8 \mathrm{~mm}$ in size) according to the description of Koyama et al. T2 signal intensities of PNMs were obtained by drawing round, elliptical or free-hand ROIs on lesions which were detected visually on the T2WI. The radiologist (M.D.) with 25 years of MRI experience who was unaware of the patients' clinical data and one pulmonologist (K.U.) with 28 years of experience evaluated the MRI data. All measures were performed by one experienced author (K.U.) supported by the experienced radiologist (M.D.). They eventually reached the same consensus. There was no discrepancy in the data between the radiologist and the pulmonologist.

\subsection{Statistical Analysis}

The data are expressed as the mean \pm standard deviation. A two-tailed Student t-test was performed for comparison of several values of two groups and ANOVA was performed for comparison of several values of three or more groups in several factors. A Chi-square test was used for the comparison of ratios. A receiver operating characteristics (ROC) curve was constructed to evaluate the diagnostic capability of the ADC value and T2 CR value in terms of malignant-benign differentiation. Using GraphPad Prism (Version 5.02, GraphPad Software, Inc. La Jolla, CA, USA) optimal cutoff values (OCVs) of ADC and $\mathrm{T} 2 \mathrm{CR}$ for a differential diagnosis were determined. The statistical analyses were performed using the computer software program StatView for Windows (Version 5.0; SAS Institute Inc. Cary, NC, USA). A $p$-value of $<0.05$ was considered statistically significant.

\section{Results}

In the ROC curve of ADC for all the PNMs, when the optimal cut off value (OCV) of ADC was set at $1.470 \times 10^{-3} \mathrm{~mm}^{2} / \mathrm{s}$, the area under the ROC curve was $74.8 \%$, the sensitivity was $84.2 \%$, and the specificity was $63.5 \%$ (Figure 1). In the ROC curve of T2 CR for all the PNMs, when the OCV of T2 CR was set at 2.45, the area under the ROC curve was $74.3 \%$, the sensitivity was $89.5 \%$, and the specificity was $65.4 \%$ (Figure 2 ).

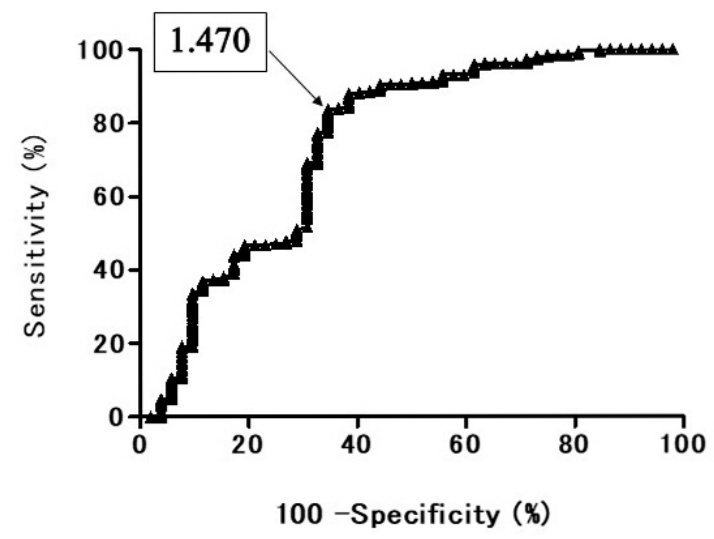

Figure 1. Receiver operating characteristic (ROC) curve shows the diagnostic performance of diffusion-weighted magnetic resonance imaging (DWI) for distinguishing benign pulmonary nodule and mass (BPNM) from lung cancer. Area under the ROC curve 74.8\%. Apparent diffusion coefficient $(\mathrm{ADC})=1.470 \times 10^{-3} \mathrm{~mm}^{2} / \mathrm{s}$, sensitivity $84.2 \%$, specificity $63.5 \%$. 


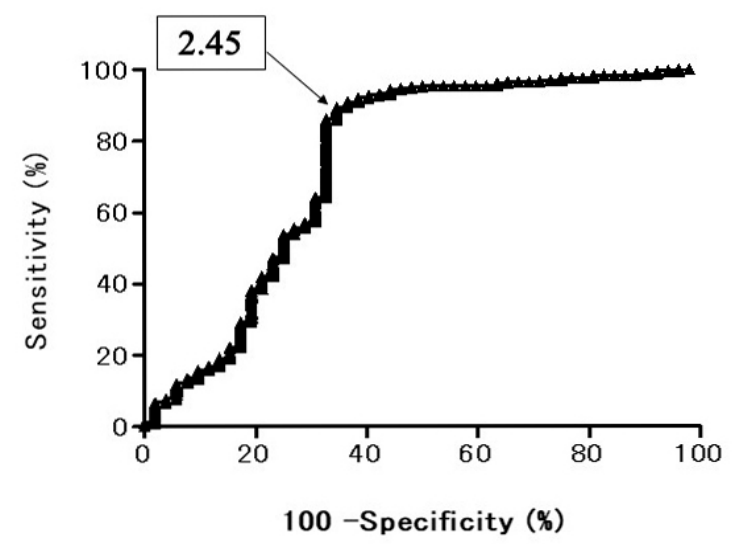

Figure 2. Receiver operating characteristic (ROC) curve shows the diagnostic performance of T2 contrast ratio (T2 CR) for distinguishing BPNM from lung cancer. Area under the ROC curve 74.3\%. $\mathrm{T} 2 \mathrm{CR}=2.45$, sensitivity $89.5 \%$, specificity $65.4 \%$.

In a Chest CT, DWI, ADC map and T2WI an adenocarcinoma and a squamous cell carcinoma are presented (Figure 3). The adenocarcinoma had $1.39 \times 10^{-3} \mathrm{~mm}^{2} / \mathrm{s}$ of ADC (True Positive: TP) and 1.67 of T2 Contrast ratio (CR) (TP). The squamous cell carcinoma had $1.04 \times 10^{-3} \mathrm{~mm}^{2} / \mathrm{s}$ of ADC (TP) and 1.25 of T2 CR (TP). In a Chest CT, DWI, ADC map and T2WI a hamartoma, a pulmonary abscess, and pulmonary tuberculosis are presented (Figure 4). The hamartoma had $2.43 \times 10^{-3} \mathrm{~mm}^{2} / \mathrm{s}$ of ADC (True Negative: TN) and 3.61 of T2 CR (TN). The pulmonary abscess had $0.837 \times 10^{-3} \mathrm{~mm}^{2} / \mathrm{s}$ of ADC (False Positive: FP) and 3.64 of T2 CR (TN). Pulmonary tuberculosis $1.85 \times 10^{-3} \mathrm{~mm}^{2} / \mathrm{s}$ of ADC (TN) and had 1.87 of T2 CR (FP).

$\mathbf{a}$
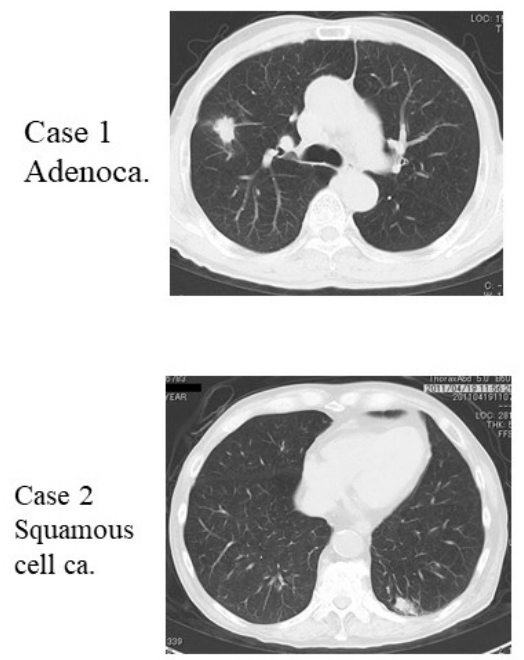

b
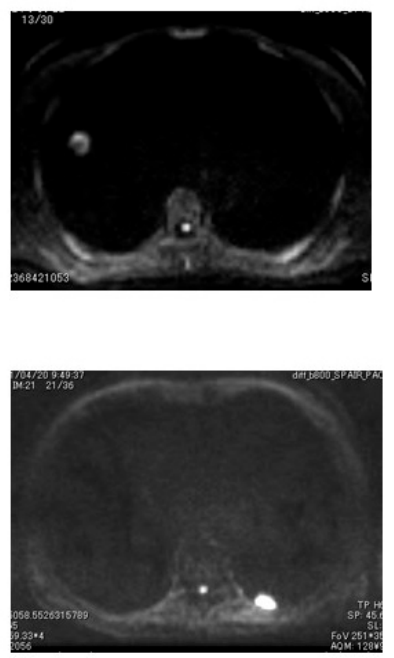

C
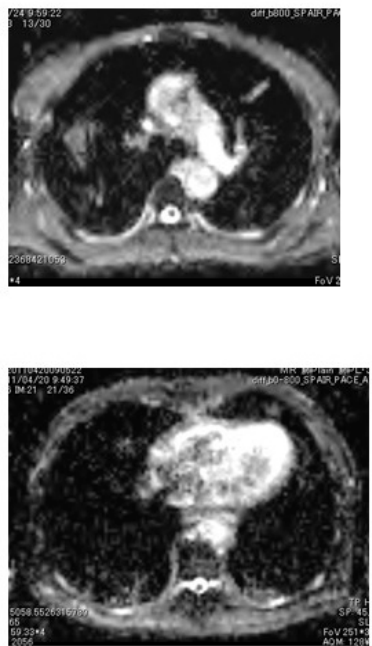

d
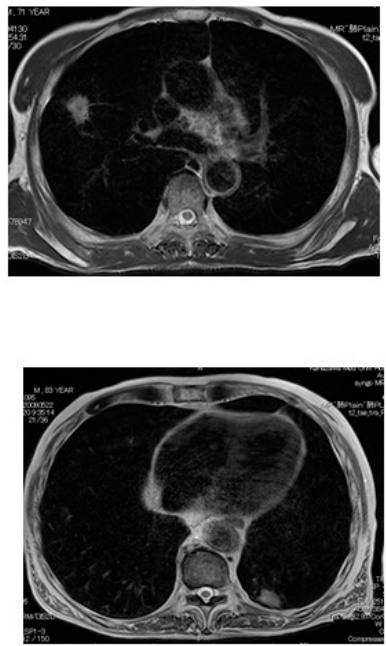

Figure 3. (a) CT, (b) DWI, (c) ADC map, (d) T2 WI. Case 1: Adenocarcinoma. ADC $1.39 \times 10^{-3} \mathrm{~mm}^{2} / \mathrm{s}, \mathrm{T} 2$ CR: 1.67 . Case2: Squamous cell carcinoma. ADC $1.04 \times 10^{-3} \mathrm{~mm}^{2} / \mathrm{s}$, T2 CR: 1.25 .

The ADC and T2 CR of lung cancers and BPNMs are shown in Figure 5. The ADC $\left(1.24 \pm 0.29 \times 10^{-3} \mathrm{~mm}^{2} / \mathrm{s}\right)$ of lung cancers was significantly lower than that $\left(1.69 \pm 0.58 \times 10^{-3} \mathrm{~mm}^{2} / \mathrm{s}\right)$ of BPNMs $(p<0.0001)$. The T2 CR $(2.01 \pm 0.52)$ of lung cancers was significantly lower than that $(2.74 \pm 1.02)$ of BPNMs $(p<0.0001)$. 
a

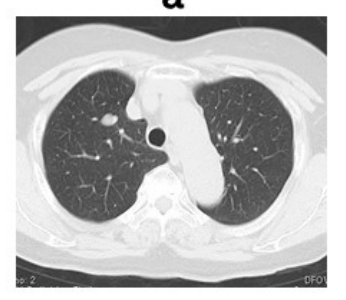

Case 3

Hamartoma

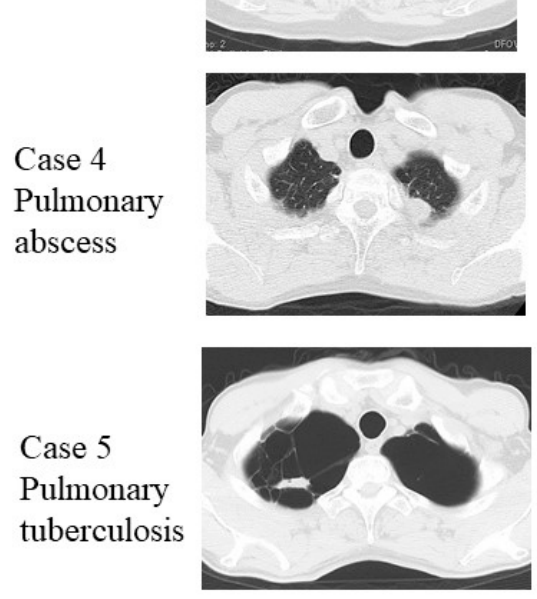

b
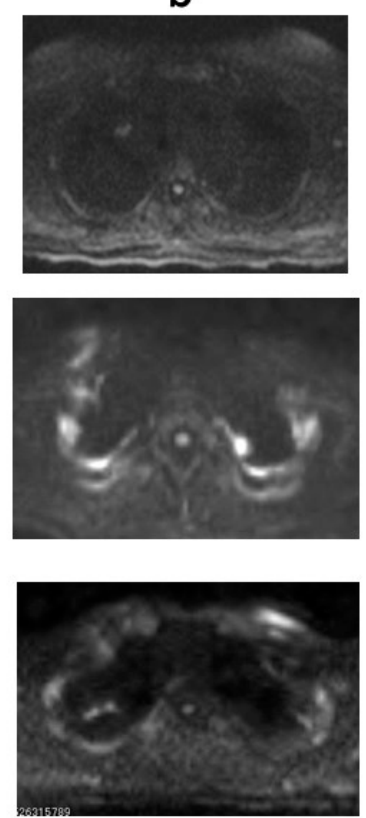

c
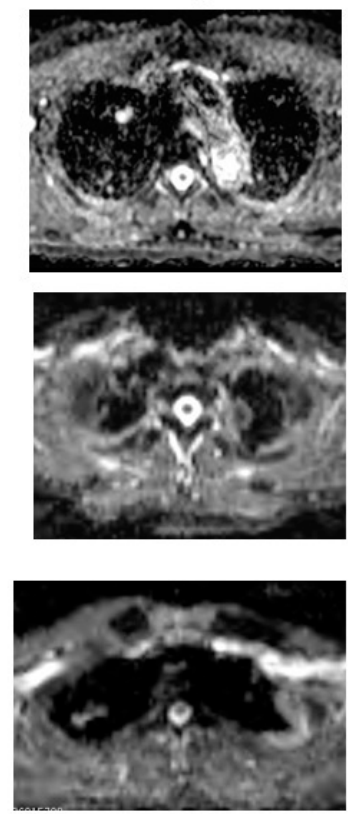

d
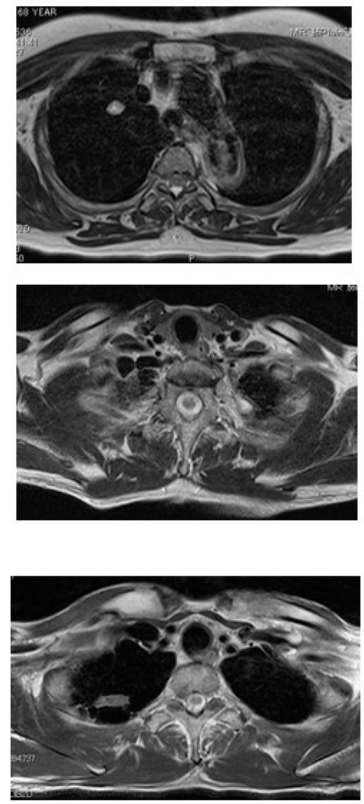

Figure 4. (a) CT, (b) DWI, (c) ADC map, (d) T2 WI. Case 3: Hamartoma, ADC $2.43 \times 10^{-3} \mathrm{~mm}^{2} / \mathrm{s}$, T2 CR: 3.61 . Case 4: Pulmonary abscess. ADC $0.837 \times 10^{-3} \mathrm{~mm}^{2} / \mathrm{s}$, T2 CR: 3.64. Case 5: Pulmonary tuberculosis. ADC $1.85 \times 10^{-3} \mathrm{~mm}^{2} / \mathrm{s}$, T2 CR:1.87.

$\times 10^{-3} \mathrm{~mm}^{2} / \mathrm{s}$
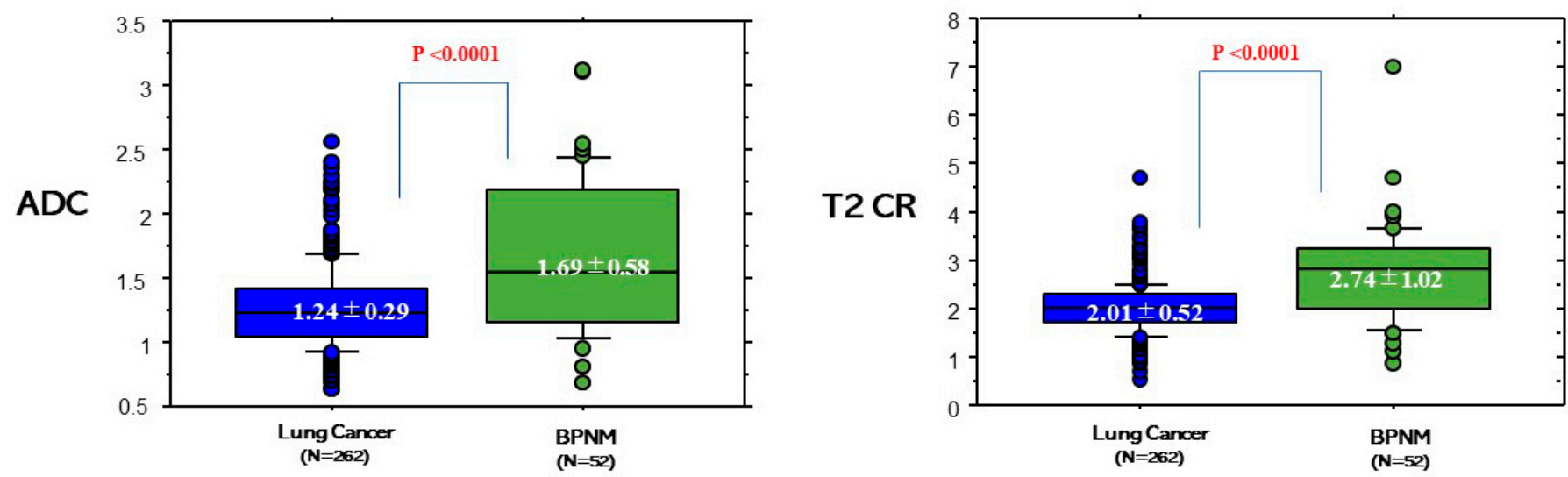

Figure 5. ADC and T2 Contrast ratio (CR) between lung cancers and BPNMs. The ADC $\left(1.24 \pm 0.29 \times 10^{-3} \mathrm{~mm}^{2} / \mathrm{s}\right)$ of lung cancers was significantly lower than that $\left(1.69 \pm 0.58 \times 10^{-3} \mathrm{~mm}^{2} / \mathrm{s}\right)$ of BPNMs $(p<0.0001)$. T2 CR was the ratio of T2 signal intensity of the pulmonary nodule divided by T2 signal intensity of a rhomboid muscle. The T2 CR (2.01 \pm 1.02$)$ of lung cancers was significantly lower than that $(2.74 \pm 1.02)$ of BPNMs $(p<0.0001)$.

ADC and T2 CR based on each diagnosis of each cell type of lung cancer and BPNM are shown in Figure 6. Although a pulmonary abscess is benign, its ADC value showed a lower ADC value (Figure 7). The ADC $\left(1.20 \pm 0.53 \times 10^{-3} \mathrm{~mm}^{2} / \mathrm{s}\right)$ of pulmonary abscesses was not significantly lower than that $\left(1.24 \pm 0.29 \times 10^{-3} \mathrm{~mm}^{2} / \mathrm{s}\right)$ of lung cancers $(p=0.695)$. The ADC $\left(1.58 \pm 0.47 \times 10^{-3} \mathrm{~mm}^{2} / \mathrm{s}\right)$ of mycobacterial infections was significantly higher than that $\left(1.24 \pm 0.29 \times 10^{-3} \mathrm{~mm}^{2} / \mathrm{s}\right)$ of lung cancers $(p<0.0001)$. On the other hand, the T2 CR (2.93 \pm 1.26$)$ of pulmonary abscesses was significantly higher than that $(2.01 \pm 0.52)$ of lung cancers $(p=0.010)$ and the T2 CR $(2.41 \pm 0.86)$ of mycobacterial infections was significantly higher than $(2.01 \pm 0.52)$ of lung cancers $(p=0.010)$. 


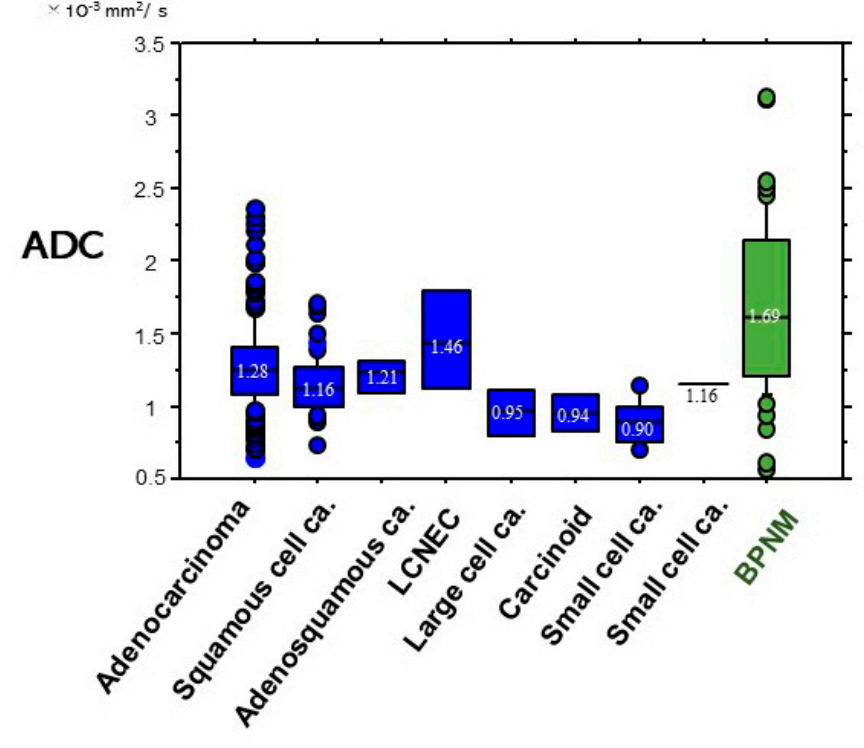

Pulmonary nodules and massess

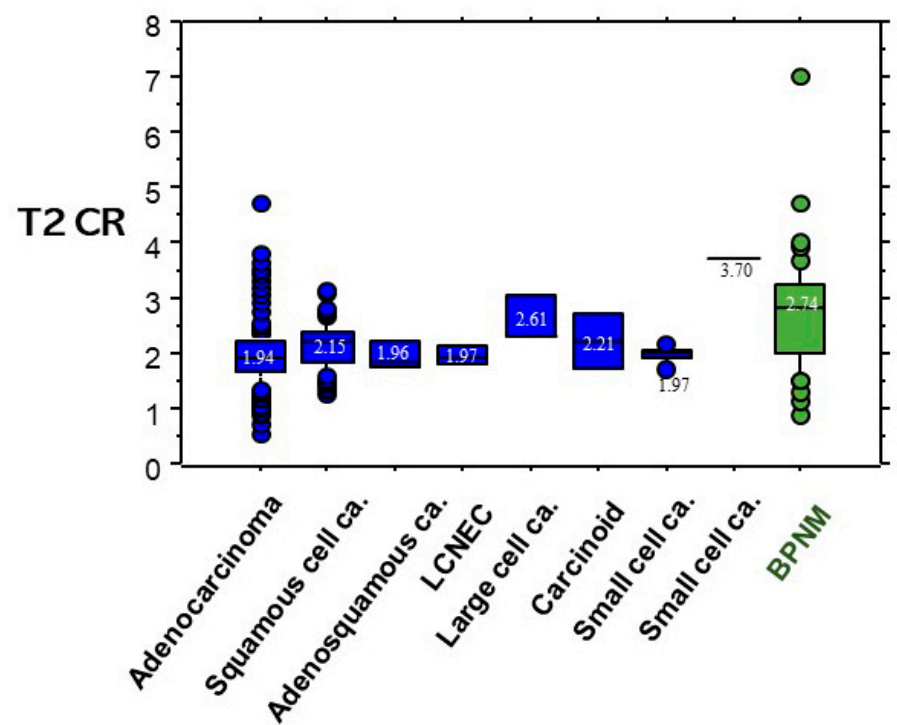

Pulmonary nodules and massess

Figure 6. ADC and T2 CR based on diagnosis of PNMs.
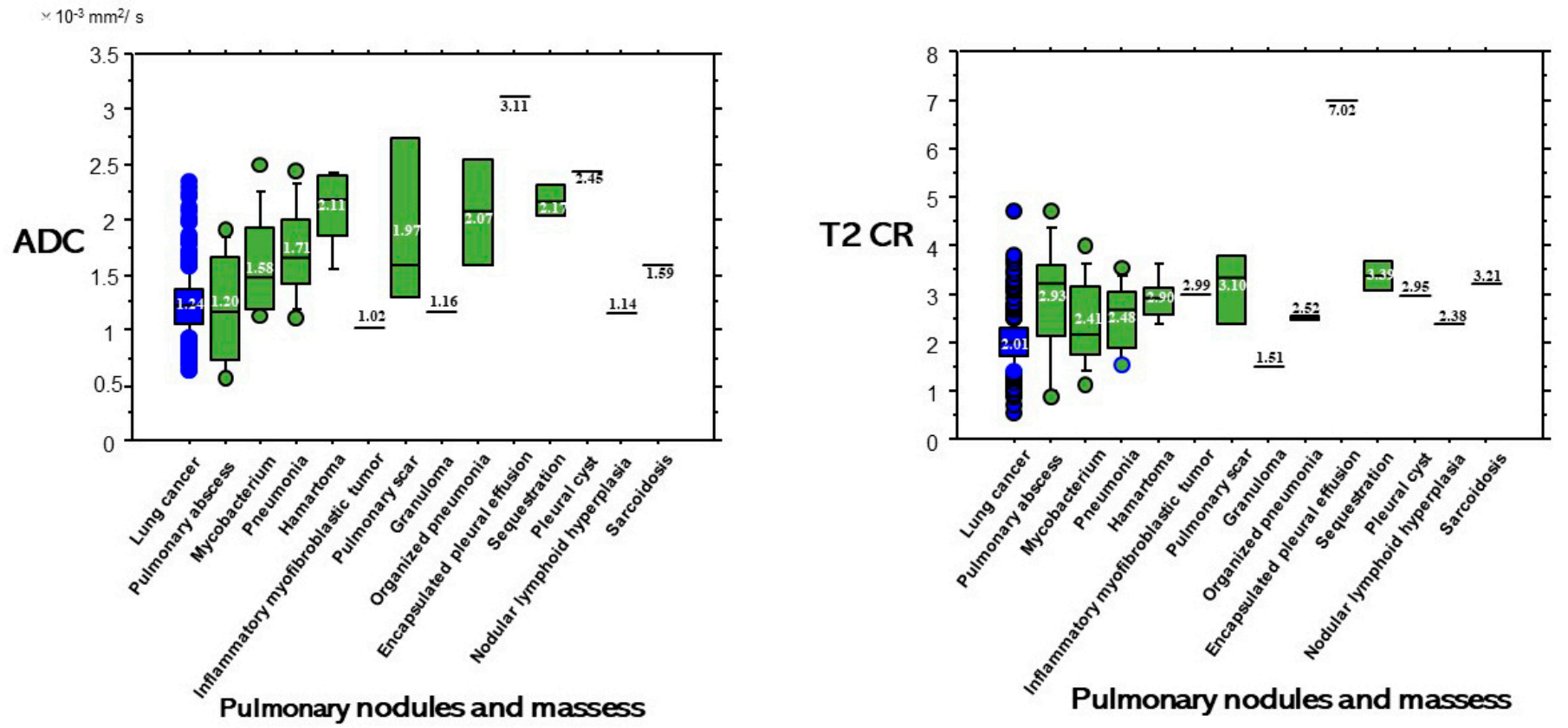

Figure 7. The $\operatorname{ADC}\left(1.20 \pm 0.53 \times 10^{-3} \mathrm{~mm}^{2} / \mathrm{s}\right)$ of pulmonary abscesses was not significantly lower than that $\left(1.24 \pm 0.29 \times 10^{-3} \mathrm{~mm}^{2} / \mathrm{s}\right)$ of lung cancers $(p=0.695)$. The ADC $\left(1.58 \pm 0.47 \times 10^{-3} \mathrm{~mm}^{2} / \mathrm{s}\right)$ of mycobacterial infections was significantly higher than that $\left(1.24 \pm 0.29 \times 10^{-3} \mathrm{~mm}^{2} / \mathrm{s}\right)$ of lung cancers $(p<0.0001)$. The T2 CR $(2.93 \pm 1.26)$ of pulmonary abscesses was significantly higher than that $(2.01 \pm 0.52)$ of lung cancers $(p=0.010)$ and the T2 CR $(2.41 \pm 0.86)$ of mycobacterial infections was significantly higher than $(2.01 \pm 0.52)$ of lung cancers $(p=0.010)$.

Concerning the pathologic subtypes (Figure 8), the ADC $\left(1.89 \pm 0.36 \times 10^{-3} \mathrm{~mm}^{2} / \mathrm{s}\right)$ of mucinous adenocarcinomas was significantly higher than that $\left(1.27 \pm 0.26 \times 10^{-3} \mathrm{~mm}^{2} / \mathrm{s}\right)$ of acinar adenocarcinomas $(p<0.0001)$, that $\left(1.27 \pm 0.23 \times 10^{-3} \mathrm{~mm}^{2} / \mathrm{s}\right)$ of papillary adenocarcinomas $(p<0.0001)$, than $\left(1.16 \pm 0.22 \times 10^{-3} \mathrm{~mm}^{2} / \mathrm{s}\right)$ of lepidic adenocarcinomas $(p<0.0001)$, than $\left(1.16 \pm 0.14 \times 10^{-3} \mathrm{~mm}^{2} / \mathrm{s}\right)$ of micropapillary adenocarcinomas $(p<0.0001)$, than $(1.10 \pm$ $\left.0.20 \times 10^{-3} \mathrm{~mm}^{2} / \mathrm{s}\right)$ of solid adenocarcinomas $(p<0.0001)$, than $\left(1.16 \pm 0.20 \times 10^{-3} \mathrm{~mm}^{2} / \mathrm{s}\right)$ of squamous cell carcinomas $(p<0.0001)$, than $\left(0.90 \pm 0.16 \times 10^{-3} \mathrm{~mm}^{2} / \mathrm{s}\right)$ of small cell car- 
cinomas $(p<0.0001)$, than $\left(1.21 \pm 0.15 \times 10^{-3} \mathrm{~mm}^{2} / \mathrm{s}\right)$ of adenosquamous carcinomas $(p<0.007)$, and than $\left(0.95 \pm 0.18 \times 10^{-3} \mathrm{~mm}^{2} / \mathrm{s}\right)$ of carcinoids $(p<0.0034)$.
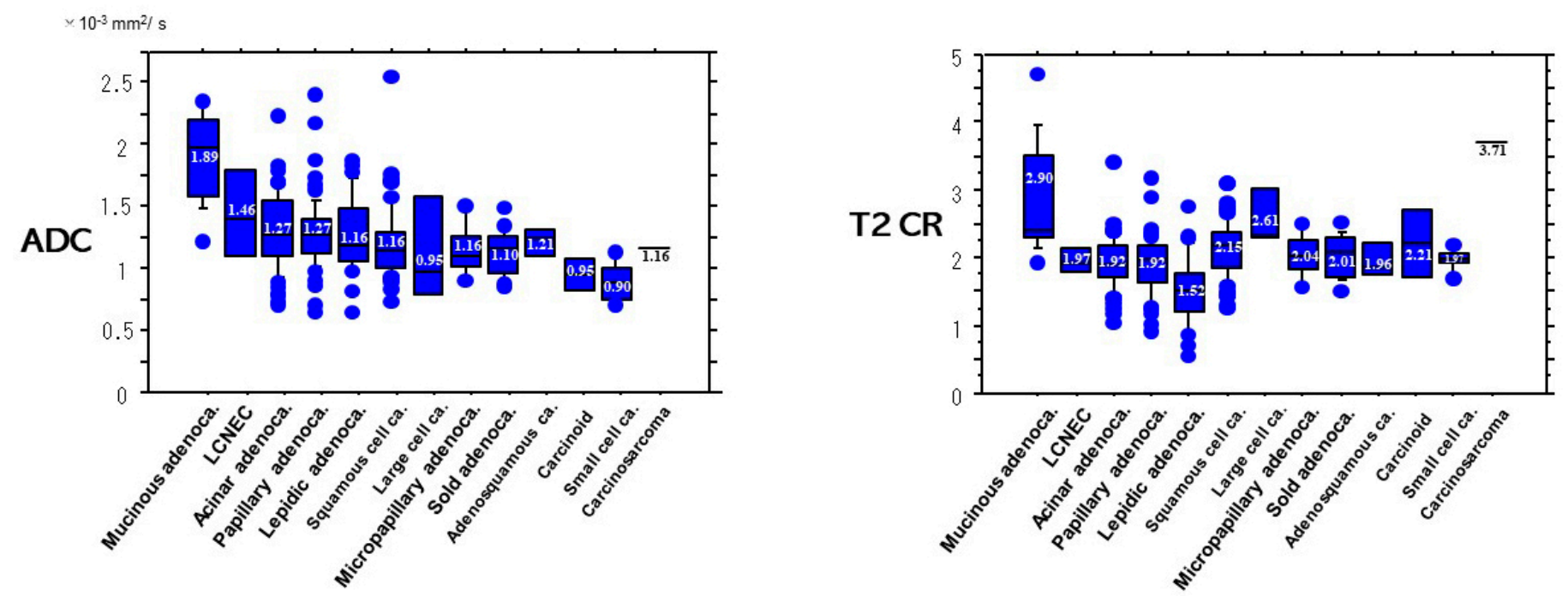

Figure 8. $\mathrm{ADC}$ and $\mathrm{T} 2 \mathrm{CR}$ based on pathologic subtypes of lung cancer. Both the ADC and the T2CR of mucinous adenocarcinoma were significantly higher than those of other pathologic subtypes.

Concerning T2WI, the T2CR $(2.90 \pm 0.83)$ of mucinous adenocarcinomas was significantly higher than that $(1.92 \pm 0.39)$ of acinar adenocarcinomas $(p<0.0001)$, that $(1.92 \pm 0.42)$ of papillary adenocarcinomas $(p<0.0001)$, than $(1.52 \pm 0.49)$ of lepidic adenocarcinomas $(p<0.0001)$, than $(2.04 \pm 0.32)$ of micropapillary adenocarcinomas $(p=0.017)$, than $(2.01 \pm 0.31)$ of solid adenocarcinomas $(p=0.0006)$, than $(2.15 \pm 0.40)$ of squamous cell carcinomas $(p<0.0001)$, and than $\left(1.97 \pm 0.16 \times 10^{-3} \mathrm{~mm}^{2} / \mathrm{s}\right)$ of small cell carcinomas $(p=0.015)$.

Concerning diagnostic efficacy of DWI for the 324 PNMs, when the OCV $(1.470 \times$ $10^{-3} \mathrm{~mm}^{2} / \mathrm{s}$ ) of ADC was applied for differential diagnosis, its sensitivity was $83.9 \%$ $(220 / 262)$, its specificity was $63.4 \%(33 / 52)$, and its accuracy was $80.6 \%(253 / 314)$. Concerning diagnostic efficacy of T2WI for the 324 PNMs, when the OCV (2.45) of T2 CR was applied for differential diagnosis, its sensitivity was $89.7 \%(235 / 262)$, its specificity was $61.5 \%(32 / 52)$, and its accuracy was 85.0\% (267/314).

Diagnostic efficacy by both DWI and T2WI is presented in Table 2. In the 212 PNMs which were judged to be malignant by both DWI and T2WI, 203 PNMs (95.8\%) were lung cancers. In 33 PNMs which were judged to be benign by both DWI and T2WI, 23 PNMs (69.7\%) were BPNMs. When DWI and T2WI had supporting results, the sensitivity [95.8\% $(203 / 212)]$ of lung cancers by both DWI and T2WI was significantly higher than that $[30.3 \%$ $(10 / 33)]$ of lung cancers which were judged as benign by both DWI and T2WI $(p<0.001)$. The specificity [69.7\% (23/33)] of BPNMs which were judged as benign by both DWI and T2WI was significantly higher than that $[4.2 \%(9 / 212)]$ of BPNMs which were judged as malignant by both DWI and T2WI $(p<0.001)$. On the other hand, the remaining $69 \mathrm{PNMs}$ had contradicting results with DWI and T2WI. When there were contradicting results, DWI was correct in $40.6 \%$ of patients (28/69), and T2WI was correct in $59.4 \%$ of patients $(41 / 69)$. 
Table 2. Diagnostic efficacy by DWI and T2WI.

\begin{tabular}{|c|c|c|c|c|c|c|c|}
\hline & & \multirow[b]{2}{*}{ Diagnosis } & \multirow[b]{2}{*}{ No. of Cases } & \multicolumn{2}{|c|}{ Supporting Results } & \multicolumn{2}{|c|}{ Contradicting Results } \\
\hline & & & & $\begin{array}{l}\text { DWI: Malignant } \\
\text { T2WI: Malignant }\end{array}$ & $\begin{array}{l}\text { DWI: Benign } \\
\text { T2WI: Benign }\end{array}$ & $\begin{array}{l}\text { DWI: Malignant } \\
\text { T2WI: Benign }\end{array}$ & $\begin{array}{c}\text { DWI: Benign } \\
\text { T2WI: Malignant }\end{array}$ \\
\hline \multirow{23}{*}{ Diagnosis } & \multirow{13}{*}{ Malignant } & Mucinous AD & 13 & $1(7.7 \%)$ & 6 & 0 & 6 \\
\hline & & Acinar AD & 58 & $44(75.9 \%)$ & 2 & 0 & 12 \\
\hline & & Papillary AD & 62 & $53(85.5 \%)$ & 0 & 2 & 7 \\
\hline & & Lepidic AD & 27 & $25(92.6 \%)$ & 1 & 0 & 1 \\
\hline & & Micropapillary AD & 7 & $6(85.7 \%)$ & 0 & 1 & 0 \\
\hline & & Solid AD & 16 & $14(87.5 \%)$ & 0 & 1 & 1 \\
\hline & & Adenosquamous ca. & 3 & $3(100 \%)$ & 0 & 0 & 0 \\
\hline & & Squamous cell ca. & 60 & $46(76.7 \%)$ & 1 & 10 & 3 \\
\hline & & LCNEC & 4 & $2(50 \%)$ & 0 & 0 & 2 \\
\hline & & Large cell ca. & 3 & $2(66.7 \%)$ & 0 & 1 & 0 \\
\hline & & Carcinoid & 2 & $1(50 \%)$ & 0 & 1 & 0 \\
\hline & & Small cell ca. & 6 & $6(100 \%)$ & 0 & 0 & 0 \\
\hline & & Carcinosarcoma & 1 & $0(0 \%)$ & 0 & 1 & 0 \\
\hline & \multirow{10}{*}{ Benign } & Total & 262 & $203(95.8 \%)$ & $10(30.3 \%)$ & $17(65.4 \%)$ & $32(74.4 \%)$ \\
\hline & & $\begin{array}{c}\text { Pneumonia/ } \\
\text { Organized pneumonia }\end{array}$ & 15 & 2 & $7(46.7 \%)$ & 2 & 4 \\
\hline & & Mycobacterial infection & 13 & 2 & $2(15.4 \%)$ & 4 & 5 \\
\hline & & Pulmonary abscess & 8 & 2 & $3(37.5 \%)$ & 2 & 1 \\
\hline & & $\begin{array}{l}\text { Pulmonary scar/ } \\
\text { Puimonary granuloma }\end{array}$ & 4 & 2 & $2(50 \%)$ & 0 & 0 \\
\hline & & Sarcoidosis & 1 & 0 & $1(100 \%)$ & 0 & 0 \\
\hline & & Hamartoma & 5 & 0 & $5(100 \%)$ & 0 & 0 \\
\hline & & Pulmonary sequestration & 2 & 0 & $1(50 \%)$ & 0 & 1 \\
\hline & & Other diseases & 4 & 1 & $2(505)$ & 1 & 0 \\
\hline & & Total & 52 & $9(4.2 \%)$ & $23(69.7 \%)$ & $9(34.6 \%)$ & $11(25.6 \%)$ \\
\hline Total & & & 314 & $212(100 \%)$ & $33(100 \%)$ & $26(100 \%)$ & $43(100 \%)$ \\
\hline
\end{tabular}




\section{Discussion}

DWI utilizes the free diffusion of water molecules and recent developments in molecular imaging based on MR techniques have provided researchers and clinicians with new tools to improve most facets of cancer care [17]. Molecular imaging is described as imaging techniques used to detect molecular signatures at the cellular and gene expression levels [17]. MRI is a particularly attractive method for molecular imaging applications, due to its noninvasive nature, outstanding signal-to-noise ratio, high spatial resolution, exceptional tissue contrast, and short imaging times [18]. Koyama et al. [16] described that non-contrast-enhanced pulmonary MRIs can effectively detect malignant nodules as well as a thin-section multidetector CT (MDCT). MRI can detect and stage lung cancer, and this method could be an excellent alternative to CT or PET/CT in the investigation of pulmonary malignancies and other diseases [19]. Conventional MRI can reveal the essential differences between mass-like tuberculosis and lung cancer and may be helpful for discriminating pulmonary masses [20]. When an invasion is unclear by CT criteria, MRI can play an important role in defining lesser degrees of invasion [21]. MRI is superior to $\mathrm{CT}$ for the visualization of the pericardium, the heart and mediastinal vessels [22]. MRI can be of use specifically for assessing invasion of the superior vena cava or myocardium, or extension of the tumor into the left atrium via pulmonary veins [22]. Although PET-CT is believed to be more accurate for this purpose, MRI has the advantage of being more universally available and less expensive [19].

DWI has been described to be able to differentiate malignancy from benignity for PNMs [7-9]. DWI is more useful for the differentiation of SCLC from NSCLC than STIR [23]. The ADC value of adenocarcinoma was significantly higher than that of either squamous cell carcinoma or small cell carcinoma, which shows that the tissue cellularity of squamous cell carcinoma or small cell carcinoma would be higher than that of adenocarcinoma [14]. ADC histogram analysis can provide important information on tumor biology in cervical cancer [24]. ADC histograms which analyze the whole tumor was reported to be useful for malignancy evaluation $[25,26]$. The pulmonary abscess has strongly restricted diffusion in DWI. Some pathological processes such as sarcoidosis, lung abscess, chronic pneumonia, pulmonary tuberculosis, nontuberculous mycobacteria, scars, and other inflammatory or infectious conditions behave like malignant lesions by exhibiting diffusion restriction [27-29]. On the other hand, carcinomas have restricted diffusion because of their high cellular proliferation rate, cells with a large size nucleus, intracellular macromolecules, high nucleus-cytoplasm rate and limited size of the extracellular matrix [30,31].

Particularly the T2WI sequence may help discriminate between progressive massive fibrosis (PMF) and lung cancer [32]. T2WI expresses liquid in the lesion brightly, and is suitable for detection of pulmonary abscess, chronic pneumonia, pulmonary tuberculosis, nontuberculous mycobacteria, and other inflammatory or infectious conditions. In this study, the T2 CR $(2.93 \pm 1.26)$ of pulmonary abscesses was significantly higher than that $(2.01 \pm 0.52)$ of lung cancers $(p=0.010)$, which proved that T2WI was useful for discriminating pulmonary abscess from lung cancer. The signal intensity ratios (SIRs) of the lesion divided by the rhomboid muscle on T2WI and T1WI were significantly different between mass-like tuberculosis and lung cancer [20]. Traditional T2WI can detect effusion in the body or in the tumor as a high signal intensity (showing white). Pleural effusion and cystic mediastinal tumors are easy to diagnose with T2WI.

We focused on not only the strengths of DWI but also the strengths of T2WI. The absolute most accurate way to reduce false positives and false negatives is to perform a biopsy. However, by using DWI and T2WI before the minimally invasive options such as serology (autoantibodies), gene chip expression platforms, and next-generation optical genome editing we will be able to get a more accurate diagnosis compared to the previous methods of CT or FDG-PET/CT. The deployment of non-invasive cancer diagnostic tools such as the use of DWI in concert with T2WI can offer potential advantages for both patients and providers. Although the diagnostic capability of both DWI plus T2WI is increasingly 
being used for PNMs one must take into account the several cases of false positives as well as false negatives by both diagnostic tools.

In this study, the ROC curve showed the diagnostic performance of DWI for distinguishing BPNM from lung cancer. The area under the ROC curve $74.8 \%$ and the sensitivity was $84.2 \%$, and the specificity was $63.5 \%$ when the OCV of ADC was at $1.470 \times 10^{-3} \mathrm{~mm}^{2} / \mathrm{s}$. The diagnostic efficacy was not a high value although the ADC $\left(1.24 \pm 0.29 \times 10^{-3} \mathrm{~mm}^{2} / \mathrm{s}\right)$ of lung cancer was significantly lower than that $\left(1.69 \pm 0.58 \times 10^{-3} \mathrm{~mm}^{2} / \mathrm{s}\right)$ of BPNMs. The ROC curve showed the diagnostic performance of T2 CR for distinguishing BPNM from lung cancer. The area under the ROC curve $74.3 \%$ and the sensitivity was $89.5 \%$, and the specificity $65.4 \%$ when the OCV of T2 CR was at 2.45 . The diagnostic efficacy was not a high value although the T2 CR $(2.01 \pm 0.52)$ of lung cancer was significantly lower than that $(2.74 \pm 1.02)$ of BPNMs $(p<0.0001)$. Combination assessment of DWI and T2WI, in 212 PNMs which were judged to be malignant by both DWI and T2WI, 203 PNMs (95.8\%) were lung cancers. In 33 PNMs which were judged to be benign by both DWI and T2WI, 23 PNMs (69.7\%) were BPNMs. The remaining 69 PNMs had contradicting results with DWI and T2WI. When there were contradicting results, DWI was correct in $40.6 \%$ of patients (28/69), and T2WI was correct in $59.4 \%$ of patients $(41 / 69)$. In cases where DWI and T2WI give contradicting results, additional examinations should be given to clarify. The combined assessment of DWI and T2WI could judge PNMs more precisely and would be acceptable for differential diagnosis of PNMs. In the literature, there were several articles concerning the diagnostic performance of DWI and T2WI for differential diagnosis for many other organs of the body, but there is no published research that focused on the lungs. This is the first paper that dealt with the combined diagnostic ability of DWI plus T2WI for differential diagnosis of PNMs. Diagnostic possibilities would be increased after fused T2WI and DWI for lung cancers and BPNMs. T2WI combined with DWI may be a valuable tool for detecting prostate cancer in the overall evaluation of prostate cancer [33,34], and myometrial invasion and staging of endometrial carcinoma [35,36]. Adding DWI to T2WI is helpful for detecting viable tumors after neoadjuvant chemoradiation therapy compared with T2WI alone or PET/CT in patients with locally advanced rectal cancer [37]. Furthermore, combining T2WI, DWI and ADC values provides increased accuracy for differentiation between benign and malignant lesions, compared with DCE (dynamic contrast-enhanced)-MRI [38].

MRI involves no radiation exposure as well as no contrast mediums and is suitable and ideal for the examination of pregnant women and children. In the next decade, MRI will be available more for PNM assessment because CT or FDG-PET/CT has some risk of radiation exposure which has to be explained to patients, who often find this unexpected. Mark L. Scheibel [39] mentioned that DWI can be used to adequately stage non-small cell lung cancer (NSCLC). If whole-body DWI can be shown to have equipoise with FDG$\mathrm{PET} / \mathrm{CT}$ for the clinical staging of NSCLC, this would reduce the costs of patient workup because 18F-FDG PET would no longer be needed. He mentioned that, in the near future, only whole-body DWI will be needed for clinical staging in patients with a new diagnosis of NSCLC.

We should keep in mind that the study had two limitations. First, it was conducted at a single institution. Further, adequately powered prospective randomized trials will be necessary to evaluate the combined assessment of DWI and T2WI for differentiating between lung cancer and BPNM.

\section{Conclusions}

In the 212 PNMs which were judged to be malignant by both DWI and T2WI, 203 PNMs (95.8\%) were lung cancers. In the 33 PNMs which were judged to be benign by both DWI and T2WI, 23 PNMs (69.7\%) were BPNMs. The combined assessment of DWI and T2WI could judge PNMs more precisely and would be acceptable for differential diagnosis of PNMs. 
Author Contributions: Conceptualization, K.U.; methodology, M.M., M.D. and K.H.; formal analysis, M.I. and S.I.; data curation, Y.I. and N.M.; methodology and software, K.H.; writing-original draft preparation, K.U.; writing-review and editing, K.U.; supervision, H.U. All authors have read and agreed to the published version of the manuscript.

Funding: This study was supported partly by a Grant-in-Aid for Scientific Research from the Ministry of Education, Culture, Sports, Science and Technology, Japan (Grant number: 20K09172).

Institutional Review Board Statement: The study protocol for examining MRI in patients with PNMs was approved by the ethical committee of Kanazawa Medical University (the approval number: No. I302). The study was conducted according to the guidelines of the Declaration of Helsinki.

Informed Consent Statement: Informed consent was obtained from all subjects involved in the study. Written informed consent has been obtained from the patient(s) to publish this paper.

Data Availability Statement: The data presented in this study are available on request from the corresponding author.

Acknowledgments: The authors are grateful to Saeko Tomida, Tatsunori Kuroda, Chihiro Nagasako, Eriko Sato, Yasuhiro Kato and Honami Sato of the MRI Center, Kanazawa Medical University, for technical assistance. The authors are grateful to Dustin Keeling for proofreading this paper.

Conflicts of Interest: All authors have no conflict of interest to declare.

\section{References}

1. Could, M.K.; Maclean, C.C.; Kuschner, W.G.; Rydzak, C.E.; Owens, D.K. Accuracy of positron emission tomography for diagnosis of pulmonary nodules and mass lesions: A meta-analysis. JAMA 2001, 285, 914-924.

2. Cheran, S.K.; Nielsen, N.D.; Patz, E.F. False-negative findings for primary lung tumors on FDG positron emission tomography. Staging and prognostic implications. Am. J. Roentgenol. 2004, 182, 1129-1132. [CrossRef] [PubMed]

3. Satoh, Y.; Ichikawa, T.; Motosugi, U.; Kimura, K.; Sou, H.; Sano, K.; Araki, T. Diagnosis of peritoneal dissemination. Comparison of 18F-DDG PET/CT, diffusion-weighted MRI, and contrast-enhanced MDCT. Am. J. Roentgenol. 2011, 196, 447-453. [CrossRef] [PubMed]

4. Goo, J.M.; Im, J.-G.; Do, K.-H.; Yeo, J.S.; Seo, J.B.; Kim, H.Y.; Chung, J.-K. Pulmonary tuberculoma evaluated by means of FDG PET. Findings in 10 cases. Radiology 2000, 216, 117-121. [CrossRef]

5. Webb, W.R.; Gatsonis, C.; Zerhouni, E.A.; Heelan, R.T.; Glazer, G.M.; Francis, I.R.; McNeil, B.J. CT and MR imaging in staging non-small cell bronchogenic carcinoma: Radiologic Diagnostic Oncology Group. Radiology 1991, 178, 705-713. [CrossRef] [PubMed]

6. Szafer, A.; Zhong, J.; Gore, J.C. Theoretical model for water diffusion in tissues. Magn. Reson. Med. 1995, 33, 697-712. [CrossRef] [PubMed]

7. Wu, L.M.; Xu, J.R.; Hua, J.; Gu, H.Y.; Chen, J.; Haacke, E.M.; Hu, J. Can diffusion-weighted imaging be used as a reliable sequence in the detection of malignant pulmonary nodules and masses? Magn. Reson. Imaging 2013, 31, 235-246. [CrossRef]

8. Li, B.; Li, Q.; Chen, C.; Guan, Y.; Liu, S. A systematic review and meta-analysis of the accuracy of diffusion-weighted MRI in the detection of malignant pulmonary nodules and masses. Acad. Radiol. 2014, 21, 21-29. [CrossRef]

9. Shen, G.; Jia, Z.; Deng, H. Apparent diffusion coefficient values of diffusion-weighted imaging for distinguishing focal pulmonary lesions and characterizing the subtype of lung cancer: A meta-analysis. Eur. Radiol. 2016, 26, 556-566. [CrossRef]

10. Fatihoğlu, E.; Biri, S.; Aydın, S.; Ergün, E.; Koşar, P.N. MRI in Evaluation of Solitary Pulmonary Nodules. Turk. Thorac. J. 2019, 20, 90-96. [CrossRef]

11. Yuen, S.; Uematsu, T.; Kasami, M.; Tanaka, K.; Kimura, K.; Sanuki, J.; Uchida, Y.; Furukawa, H. Breast carcinomas with strong high-signal intensity on T2-weighted MR images: Pathological characteristics and differential diagnosis. J. Magn. Reson. Imaging 2007, 25, 502-510. [CrossRef]

12. Uematsu, T. Focal breast edema associated with malignancy on T2-weighted images of breast MRI: Peritumoral edema, prepectoral edema, and subcutaneous edema. Breast Cancer 2015, 22, 66-70. [CrossRef] [PubMed]

13. Satoh, S.; Kitazume, Y.; Ohdama, S.; Kimula, Y.; Taura, S.; Endo, Y. Can malignant and benign pulmonary nodules be differentiated with diffusion-weighted MRI? Am. J. Roentgenol. 2008, 191, 464-470. [CrossRef] [PubMed]

14. Usuda, K.; Iwai, S.; Yamagata, A.; Sekimura, A.; Motono, N.; Matoba, M.; Doai, M.; Yamada, S.; Ueda, Y.; Hirata, K.; et al. Relationships and Qualitative Evaluation Between Diffusion-Weighted Imaging and Pathologic Findings of Resected Lung Cancers. Cancers 2020, 12, 1194. [CrossRef] [PubMed]

15. Brierley, J.D.; Gospodarowicz, M.K.; Wittekind, C. TNM Classification of Malignant Tumours, 8th ed.; John Wiley \& Sons: Hong Kong, China, 2017.

16. Koyama, H.; Ohno, Y.; Kono, A.; Takenaka, D.; Maniwa, Y.; Nishimura, Y.; Ohbayashi, C.; Sugimura, K. Quantitative and qualitative assessment of non-contrast-enhanced pulmonary MR imaging for management of pulmonary nodules in 161 subjects. Eur. Radiol. 2008, 18, 2120-2131. [CrossRef] [PubMed] 
17. Haris, M.; Yadav, S.K.; Rizwan, A.; Singh, A.; Wang, E.; Hariharan, H.; Reddy, R.; Marincola, F.M. Molecular magnetic resonance imaging in cancer. J. Transl. Med. 2015, 13, 1-16. [CrossRef] [PubMed]

18. Winter, P.M.; Caruthers, S.D.; Wickline, S.A.; Lanza, G.M. Molecular imaging by MRI. Curr. Cardiol. Rep. 2006, 8, 65-69. [CrossRef]

19. Hochhegger, B.; Marchiori, E.; Sedlaczek, O.; Irion, K.; Pheussel, C.P.; Ley, S.; Ley-Zaporozhan, J.; Soares Souza, A., Jr.; Kauczor, H.U. MRI in lung cancer: A pictorial essay. Br. J. Radiol. 2011, 84, 661-668. [CrossRef]

20. Qi, L.-P.; Chen, K.-N.; Zhou, X.J.; Tang, L.; Liu, Y.-L.; Li, X.-T.; Wang, J.; Sun, Y.-S. Conventional MRI to detect the differences between mass-like tuberculosis and lung cancer. J. Thorac. Dis. 2018, 10, 5673-5684. [CrossRef]

21. Ohno, Y.; Koyama, H.; Dinkel, J.; Hintze, C. Lung cancer. In MRI of the Lung; Kauczor, H.U., Ed.; Springer: Berlin/Heidelberg, Germany, 2009; pp. 179-216.

22. Ohno, Y.; Adachi, S.; Motoyama, A.; Kusumoto, M.; Hatabu, H.; Sugimura, K.; Kono, M. Multiphase ECG triggered 3D contrastenhanced MR angiography: Utility for evaluation of hilar and mediastinal invasion of bronchogenic carcinoma. J. Magn. Reason. Imaging 2001, 13, 215-224. [CrossRef]

23. Koyama, H.; Ohno, Y.; Nishio, M.; Takenaka, D.; Yoshikawa, T.; Matsumoto, S.; Seki, S.; Maniwa, Y.; Ito, T.; Nishimura, Y.; et al. Diffusion-weighted imaging vs. STIR turbo SE imaging: Capability for quantitative differentiation of small-cell lung cancer from non-small-cell lung cancer. Br. J. Radiol. 2014, 87, 20130307. [CrossRef] [PubMed]

24. Schob, S.; Meyer, H.J.; Pazaitis, N.; Schramm, D.; Bremicker, K.; Exner, M.; Höhn, A.K.; Garnov, N.; Surov, A.; Schob, S.; et al. ADC Histogram Analysis of Cervical Cancer Aids Detecting Lymphatic Metastases-a Preliminary Study. Mol. Imaging Biol. 2017, 19, 953-962. [CrossRef] [PubMed]

25. Xue, H.; Ren, C.; Yang, J.; Sun, Z.; Li, S.; Jin, Z.; Shen, K.; Zhou, W. Histogram Analysis of Apparent Diffusion Coefficient for the Assessment of Local Aggressiveness of Cervical Cancer. Arch. Gynecol. Obstet. 2014, 290, 341-348. [CrossRef]

26. Donati, O.F.; Mazaheri, Y.; Afaq, A.; Vargas, H.A.; Zheng, J.; Moskowitz, C.S.; Hricak, H.; Akin, O. Prostate Cancer Aggressiveness: Assessment with Whole-Lesion Histogram Analysis of the Apparent Diffusion Coefficient. Radiology 2014, 271, 143-152. [CrossRef]

27. Liu, H.; Liu, Y.; Yu, T.; Ye, N. Usefulness of diffusion-weighted MR imaging in the evaluation of pulmonary lesions. Eur. Radiol. 2010, 20, 807-815. [CrossRef] [PubMed]

28. Coolen, J.; De Keyzer, F.; Nafteux, P.; De Wever, W.; Dooms, C.; Vansteenkiste, J.; Roebben, I.; Verbeken, E.; De Leyn, P.; Van Raemdonck, D.; et al. Malignant pleural disease: Diagnosis by using diffusion-weighted and dynamic contrast-enhanced MR imaging-initial experience. Radiology 2012, 263, 884-892. [CrossRef]

29. Usuda, K.; Sagawa, M.; Motono, N.; Ueno, M.; Tanaka, M.; Machida, Y.; Maeda, S.; Matoba, M.; Kuginuki, Y.; Taniguchi, M.; et al. Diagnostic performance of diffusion-weighted imaging of malignant and benign pulmonary nodules and masses: Comparison with positron emission tomography. Asian Pac. J. Cancer Prev. 2014, 15, 4629-4635. [CrossRef]

30. Henzler, T.; Schmid-Bindert, G.; Schoenberg, S.O.; Fink, C. Diffusion and perfusion MRI of the lung and mediastinum. Eur. J. Radiol. 2010, 76, 329-336. [CrossRef]

31. Lyng, H.; Haraldseth, O.; Rofstad, E.K. Measurement of cell density and necrotic fraction in human melanoma xenografts by diffusion weighted magnetic resonance imaging. Magn. Reason. Med. 2000, 43, 828-836. [CrossRef]

32. Ogihara, Y.; Ashizawa, K.; Hayashi, H.; Nagayasu, T.; Hayashi, T.; Honda, S.; Uetani, M. Progressive massive fibrosis in patients with pneumoconiosis: Utility of MRI in differentiating from lung cancer. Acta Radiol. 2018, 59, 72-80. [CrossRef]

33. Wu, L.-M.; Xu, J.-R.; Ye, Y.-Q.; Lu, Q.; Hu, J.-N. The clinical value of diffusion-weighted imaging in combination with T2-weighted imaging in diagnosing prostate carcinoma: A systematic review and meta-analysis. Am. J. Roentgenol. 2012, 199, 103-110. [CrossRef]

34. Syer, T.J.; Godley, K.C.; Cameron, D.; Malcolm, P.N. The diagnostic accuracy of high b-value diffusion- and $\mathrm{T}_{2}$-weighted imaging for the detection of prostate cancer: A meta-analysis. Abdom. Radiol. 2018, 43, 1787-1797. [CrossRef] [PubMed]

35. Guo, Y.; Wang, P.; Wang, P.; Gao, W.; Li, F.; Yang, X.; Ni, H.; Shen, W.; Guo, Z. Myometrial invasion and overall staging of endometrial carcinoma: Assessment using fusion of T2-weighted magnetic resonance imaging and diffusion-weighted magnetic resonance imaging. Onco. Targets Ther. 2017, 10, 5937-5943. [CrossRef] [PubMed]

36. Deng, L.; Wang, Q.-P.; Chen, X.; Duan, X.-Y.; Wang, W.; Guo, Y.-M. The Combination of Diffusion- and T2-Weighted Imaging in Predicting Deep Myometrial Invasion of Endometrial Cancer: A Systematic Review and Meta-Analysis. J. Comput. Assist. Tomogr. 2015, 39, 661-673. [CrossRef] [PubMed]

37. Song, I.; Kim, S.H.; Lee, S.J.; Choi, J.Y.; Kim, M.J.; Rhim, H. Value of diffusion-weighted imaging in the detection of viable tumour after neoadjuvant chemoradiation therapy in patients with locally advanced rectal cancer: Comparison with $T_{2}$ weighted and PET/CT imaging. Br. J. Radiol. 2012, 85, 577-586. [CrossRef] [PubMed]

38. Kim, K.W.; Kuzmiak, C.M.; Kim, Y.J.; Seo, J.Y.; Jung, H.K.; Lee, M.S. Diagnostic Usefulness of Combination of Diffusion-weighted Imaging and T2WI, Including Apparent Diffusion Coefficient in Breast Lesions: Assessment of Histologic Grade. Acad. Radiol. 2018, 25, 643-652. [CrossRef] [PubMed]

39. Schieble, M.L. Can solitary pulmonary nodules be accurately characterized with diffusion-weighted MRI? Radiology 2019, 290, 535-536. [CrossRef] 